\section{B A Institute of \\ YK Business Administration \\ 六下 \\ Karachi \\ Leadership and Ideas for Tomorrow}

Business Review

Volume 14 Issue 2 July-December 2019

7-1-2019

\title{
Empirical estimation of urban life cycle using the three dimensional Lotka-Volterra model
}

\author{
Minhaj Uddin Siddiqui \\ Applied Economics Research Center, University of Karachi, Pakistan \\ Shaista Alam \\ Applied Economics Research Center, University of Karachi, Pakistan
}

Follow this and additional works at: https://ir.iba.edu.pk/businessreview

\section{c) (i)}

This work is licensed under a Creative Commons Attribution 4.0 International License.

\section{Recommended Citation}

Siddiqui, M. U., \& Alam, S. (2019). Empirical estimation of urban life cycle using the three dimensional Lotka-Volterra model. Business Review, 14(2), 116-127. Retrieved from https://doi.org/10.54784/ 1990-6587.1020

This article is brought to you by iRepository for open access under the Creative Commons Attribution 4.0 License and is available at https://ir.iba.edu.pk/businessreview/vol14/iss2/7. For more information, please contact irepository@iba.edu.pk. 


\title{
Empirical estimation of urban life cycle using the three dimensional Lotka-Volterra Model
}

\author{
Minhaj Uddin Siddiqui · Shaista Alam
}

\begin{abstract}
This paper addresses the issues of urban growth sustainability by emphasizing on urban life cycle dynamics and its determinants with respect to the issues of environmental quality. A number of qualitative models have been discussed in order to understand urban dynamics. This paper empirically estimates the parameters of the mathematical model by the interaction of urban population, urban rent and urban income in the framework of the three dimensional Lotka-Volterra model. Numerical simulations of international cities are divided into five categories. The results confirm the cyclic behavior of the three variables with little difference in significance level. The findings of this paper and the application of the three dimensional Lotka Volterra Model can be used for policy formulation for future urban planning.
\end{abstract}

Keywords Urban life cycle - Lotka-Volterra - Three dimensional systems.

\section{Introduction}

Urban cities are the major cause of environmental pollution. As urban city size is important for urban long-term sustainability hence, it is also important for urban life cycle dynamics and its determinants with the issue of population growth cycles in order to bring quality changes in urban living conditions.

Urban life cycle has been theoretically described by Berg et al (1982) as a descriptive model which observes the changes in population growth patterns overtime in relation to city area and periphery. There is a cyclical relationship between the city area and the periphery as suggested by the comparative trend analysis of demography of the cities which is briefly discussed in four phases; i.e. Urbanization, Suburbanization, De-urbanization and Re-urbanization.

Minhaj Uddin Siddiqui

Applied Economics Research Center, University of Karachi, Pakistan

E-mail: minhajus@yahoo.com

Shaista Alam

Applied Economics Research Center, University of Karachi, Pakistan 
Approximately, more than one half of the world's population is now living in cities, therefore, cities are considered as the engine of economic growth and prosperity. It is therefore necessary to understand the urban life cycle dynamics. In previous literature, various models have studied dynamics of urban life cycle with the interaction of two variables in the Lotka-Volterra type models. These models use urban population, per capita income and urban land rent in the pair of two variables to describe urban growth behavior in the stages of the urban life cycle.

Urban dynamics have been studied and analyzed with different theoretical arguments in this paper. The present paper discusses urban life cycle theory to interpret urban life cycle dynamics in terms of phases. The objective of the study is to obtain the empirical estimates of parameters using panel fixed effect regression with real data of thirty international cities to simulate the three dimensional non linear Lotka-Volterra Model to determine urban life cycle dynamics empirically during the time period 2000 to 2016.

The three dimensional Lotka Volterra Model used in this paper is primarily an economic model that assesses the relationship between population growth, per capita income and land rent of urban areas. It effectively interprets demographic changes and allows in-depth analysis.

This research work is the first attempt to present empirical estimates and numerical simulations of the three dimensional Lotka-Volterra Model with the real data of thirty international cities to describe dynamics of urban life cycle which was previously in different studies explained by the movement of urban population and later described by the interaction between two variables.

The remaining part of the paper is organized as follows: section 2 of the research paper presents a description of urban life cycle dynamics and three dimensional Lotka-Volterra Model for urban life cycle. Section 3 presents the empirical structure of the model. Section 4 describes the cities data and types of cities selected for the empirical estimation and data sources. Section 5 contains the empirical estimates of the parameters and simulations by types of cities and overall. Section 6, presents the conclusion of the research paper.

\section{Literature review}

The ecological prey-predator model was first introduced by Lotka (1926) and Volterra (1931) and effectively applied in urban economics by Dendrinos and Mullally (1981, 1983); Orishimo (1987); Camagni (2016) as discussed in this research paper. The biological prey-predator model describes a competitive environment between two species that is prey and predator. This model shows the indirect relationship between the population of prey and predator that is if the population of prey increases, population of predator decreases and this cyclical relationship continues. The prey-predator model gives a strong role to economic reasoning in the explanation of urban dynamics.

The study further discusses each model as proposed by Dendrinos and Mullally (1981, 1983); Orishimo (1987); Camagni (2016). According to which Dendrinos and Mullally $(1981,1983)$ applies the Lotka-Volterra Model to urban 
dynamics by specifying urban population as predator and per-capita income as prey. According to them, an increase in income attracts new population and as a result the population starts to increase which causes decrease in per capita income because of diseconomies of scale. The population commutes to other places due to low income and the cycle continues.

Orishimo (1987) presents an opposite logic to that proposed by Dendrinos and Mullally. It uses population $(\mathrm{N})$ as prey and land price $(\mathrm{r})$ as the predator. This model suggests a mechanism according to which, population growth generates greater investment in production processes which leads to increase in the stock of cumulated capital (r). This increase in the stock of cumulated capital in turn yields negative feedback mechanisms for population growth. But Dendrinos and Mullally model and Orishimo model are both subject to the same criticism that is, the equations applied are valid but they are only applicable to the cities where congestion phenomenon and diseconomies of scale are extremely essential.

Camagni (2016) interpreted the role of rents based on prey-predator model and finds its basis in Ricardian rent theory. In his model, urban rent plays a role in distribution of total urban income and as an allocator of resources at territorial level. This model includes two main variables; urban income $(\mathrm{Y})$ and urban rent $(r)$. As the urban income increases which is generated by the technological processes, the urban land values also increase which leads to higher urban rents and consequently decreases production profits for entrepreneurs. The model does not represent the population as prey as in the Orishimo model and replaced it by urban income. It purely uses the economic variable urban rent instead of physical variable. Although both Orishimo and Camagni models present urban rent as predator yet both follow different economic logic. In short, from both the models, it is concluded that an increase in urban rent is considered as an additional cost that pushes population out from the core areas to peripheral areas. Urban rent influence location choices and thus serves as a spatial resource allocator.

\section{Theoretical underpinning}

3.1 Dynamics of urban life cycle

The theory of spatial cycle (SCT) was introduced by Klaassen et al (1981). Berg et al (1982) has made different investigations of urban growth patterns, based mostly on employment and migration. The urban agglomerations are classified into two parts; the center area and the surrounding (ring) area. The stages of city development can then be represented by the advancement of both the surrounding and the city areas, which depends upon the growth rate of center and surrounding of the city. According to SCT, development of the urban areas may be explained by using four phases: (i) urbanization, (ii) sub-urbanization (iii) de-urbanization, and (iv) reurbanization.

In the first phase of the cycle that is urbanization, the economic affairs and the population moves to the inner city from suburbs at a great extent. The 
increase in financial and institutional power, infrastructural development and the development of tertiary and secondary sectors in city areas creates ideal conditions for urbanization. But due to the increase in population growth and economic activities within the center of the city, other factors like traffic, pollution, crimes and poverty also increase. High and medium income households start moving towards the periphery areas with favorable housing conditions and high quality of environment.

Thus, second stage of the spatial cycle, suburbanization, takes place when the movement of population from the urban core to the surroundings takes place. Bourne (1996) interpreted suburbs as; (i) a mechanism to escape social and environmental problems common in the central city (ii) a macro-economic tool (iii) a means of individual utility maximization and (iv) a means of sociopolitical strategies.

The stage of suburbanization is completed with the companies reestablishment and population over concentration in the suburban region and the third stage de-urbanization begins. The de-urbanization stage is completed by the emergence of unfavorable conditions into the over concentrated suburbs and population migration in the new cities where the quality of the environment living standards are more desirable .

In the last phase of the spatial cycle, re-urbanization, the decrease in population in core city, in parallel, gentrification, that was observed in de-urbanization stage; starts to vanish (Lever 1993). The capability of modernizing the housing conditions of the inner city forms the basic factor of evolution discussed above. In this stage, population of the core city increases while the population of suburbs decreases due to change in the economic structure of the urban region, development of high-technology tertiary sector and change in energy and transportation costs in the center of the city.

\subsection{The three dimensional Lotka Volterra Model}

The model we proposed in our previous paper was the first attempt at application of the three dimensional prey and predator model in urban economics. Through this model, we describe the dynamics of urban life cycle by using three dimensional Lotka-Volterra models, which was traditionally done only by the movement of population and afterwards explained by the interaction of two variables. Three dimensional systems provide more in-depth analysis of urban life cycle dynamics.

\subsubsection{Model structure}

The three Lotka-Volterra models of Dendrinos and Mullally (1981, 1983); Orishimo (1987); Camagni (2016) that study urban life cycle growth dynamics are of our interest because we obtain our model specifications and assumptions from these prey-predator type models of urban dynamics. In these three models, the dynamic behavior of three variables in the pair of two was analyzed to describe urban life cycle. Dendrinos and Mullally $(1981,1983)$ described urban dynamics with the cyclical relationship between urban population and urban income. 
Orishimo (1987) described the four stages of urban life cycle by the cyclical behavior of urban population and urban rent while Camagni (2016) described it by the cyclical behavior of urban income and urban rent. Both the Orishimo and Camagni models presented urban rent as the predator.

We proposed our model as the Lotka-Volterra type model by assuming same kind of behavior of the three variables that is population as predator for income, income as prey for both population and urban rent and urban rent with its dual behavior as predator for both income and population in city area. A driving force or indicator is essential to work behind the dynamics of two variables because we assume that only two variables could not define the dynamics of urban life cycle completely. We assume that income could be an indicator behind the dynamics of population and urban rent in an urban core area. On the other hand urban rent could be a driving force behind the dynamics of population and income of an urban core area.

We combine the three variables that is urban population, urban income and urban rent in the three dimensional Lotka-Volterra model. We include logistic behavior instead of exponential behavior of population and income growth. By combining these three indicators we have been able to provide more in depth analysis of behavior of urban dynamics in the context of the urban life cycle. The proposed model is a three dimensional system of non-linear differential equation as follows:

$$
\begin{gathered}
d P / d t=P\left(a_{1} b_{1 r}+e_{1} Y f_{1} P\right) \\
d Y / d t=Y\left(a_{2} b_{2 r} e_{2} P f_{2} Y\right) \\
d r / d t=r\left(c+d_{1} P+d_{2} Y\right)
\end{gathered}
$$

where, $P=$ Population of urban city, $Y=$ Income of urban city, $r=$ Urban rent, $d P / d t=$ Time derivative of Population represents growth rate of Population with respect to time, $d Y / d t=$ Time derivative of Income represents growth rate of Income with respect to time and $d r / d t=$ Time derivative of Urban Rent represents growth rate of Urban Rent with respect to time.

\subsubsection{Coefficients}

The coefficients have been defined as follows. $a_{1}=$ Population Initial growth rate, $a_{2}=$ Income Initial growth rate, $c=$ Urban rent initial decay rate, $b_{1}=$ interaction effect rate of urban rent in population growth, $b_{2}=$ interaction effect rate of urban rent in income growth, $d_{1}=$ interaction effect rate of population in urban rate growth. $d_{2}=$ interaction effect rate of income in urban rent growth, $e_{1}$ $=$ interaction effect rate of income in population growth, $e_{2}=$ interaction effect rate of population in income growth, $f_{1}=$ coefficient of population square term for logistic function, $f_{2}=$ coefficient of income square term for logistic function. The carrying capacity of the city for population is $a_{1} / f_{1}$ and for income $a_{2} / f_{2}$. 


\subsubsection{Empirical structure of three dimensional Lotka Volterra Model}

In this section we present the empirical structure of our three dimensional LotkaVolterra Model. This econometric model is used for the empirical estimate of the prey predator model. The methodology adopted in this section of the work is a time series cross-section model. We use the three non linear differential equations from above and convert the instantaneous rate of change into the average rate of change with respect to change in time. The derivatives will convert into the differences of the variable in the discrete sense. Therefore, we can write the above three differential equations in the form of discrete difference equations. Empirically:

$$
\begin{gathered}
\Delta P_{i t} / P_{i t}=a_{1 i}-b_{1 i} r_{i t-1}+e_{1 i} Y_{i t-1}-f_{1 i} P_{i t-1}+\varepsilon_{p i t} \\
\Delta Y_{i t} / Y_{i t}=a_{2 i}-b_{2 i} r_{i t-1}-e_{2 i} P_{i t-1}-f_{2 i} Y_{i t-1}+\varepsilon_{y i t} \\
\Delta r_{i t} / r_{i t}=-c_{i}+d_{1 i} P_{i t-1}+d_{2 i} Y_{i t-1}+\varepsilon_{r i t}
\end{gathered}
$$

The three dependent variables of the above equations become, respectively, the percentage change of population, income and urban rent. Scale effects, which may occur in cross-section analyses and generate problems in the interpretation of the values of the parameters, are overcome thanks to the fact that changes are not calculated in absolute terms. The independent variables of the empirical model are, respectively, calculated with a time lag with respect to the dependent variables. The time lag is justified by the idea that agents are very likely to adjust to changes in house prices with a delay due to the difficulties involved in the decision to move. On the other hand, prices can adjust more rapidly, but rigidities in the housing market (such as planning regulations or the existing housing stock which cannot be easily reconverted) can cause a delay also on this side of the adjustment process. The matrix notation is as follows:

$$
\left(\begin{array}{c}
\Delta P_{i t} / P_{i t} \\
\Delta Y_{i t} / Y_{i t} \\
\Delta r_{i t} / r_{i t}
\end{array}\right)=\left(\begin{array}{c}
a_{1 i} \\
a_{2 i} \\
-c_{i}
\end{array}\right)+\left(\begin{array}{ccc}
-f_{1 i} & e_{1 i} & -b_{1 i} \\
-e_{2 i} & -f_{2 i} & -b_{2 i} \\
d_{1 i} & d_{2 i} & 0
\end{array}\right) *\left(\begin{array}{c}
P_{i t-1} \\
Y_{i t-1} \\
r_{i t-1}
\end{array}\right)+\left(\begin{array}{l}
\varepsilon_{p i t} \\
\varepsilon_{y i t} \\
\varepsilon_{\text {rit }}
\end{array}\right)
$$

Now suppose,

$$
\begin{gathered}
\Delta V_{i t}=\left(\begin{array}{c}
\Delta P_{i t} / P_{i t} \\
\Delta Y_{i t} / Y_{i t} \\
\Delta r_{i t} / r_{i t}
\end{array}\right), \alpha_{i}=\left(\begin{array}{c}
a_{1 i} \\
a_{2 i} \\
-c_{i}
\end{array}\right), \beta_{i}=\left(\begin{array}{ccc}
-f_{1 i} & e_{1 i} & -b_{1 i} \\
-e_{2 i} & -f_{2 i} & -b_{2 i} \\
d_{1 i} & d_{2 i} & 0
\end{array}\right) \\
V_{i t-1}=\left(\begin{array}{c}
P_{i t-1} \\
Y_{i t-1} \\
r_{i t-1}
\end{array}\right), \varepsilon_{i t}=\left(\begin{array}{c}
\varepsilon_{p i t} \\
\varepsilon_{y i t} \\
\varepsilon_{r i t}
\end{array}\right)
\end{gathered}
$$

Elements of the matrix $\Delta V_{i t}$ represent the corresponding dependent variable. Elements of the matrix $\alpha_{i}$ represents the growth rate of the corresponding dependent variable, which is independent of the changes in the two other variables. Elements of the coefficient matrix $\beta_{i}$ represent the interactive effect of variables 
in the growth of the dependent variable respectively by column. Elements of the coefficient matrix $\varepsilon_{i t}$ represent the error terms captured by the effect of other city related variables independently. Therefore,

$$
\Delta V_{i t}=\alpha_{i}+\beta_{i} * V_{i t-1}+\varepsilon_{i t}
$$

The above matrix form of the empirical model could be applied to the real data of cities for estimation of parameters and also for forecasting the future values of the variables to analyze the future of the cities for policy implications.

\subsubsection{Equilibrium steady state}

For steady state equilibrium points

$$
\begin{gathered}
P\left(a_{1} b_{1 r}+e_{1} Y f_{1} P\right)=0 \\
Y\left(a_{2} b_{2 r} e_{2} P f_{2} Y\right)=0 \\
r\left(c+d_{1} P+d_{2} Y\right)=0
\end{gathered}
$$

by solving the above simultaneously, we found seven equilibriums point of our model. The very obvious equilibrium point is origin $A(0,0,0)$. One equilibrium point in on P-axis i.e. $B\left(a_{1} / f_{1}, 0,0\right)$ obviously that point shows level of population survival without income and urban rent. Similarly, another point i.e. $C\left(0, a_{2} / f_{2}, 0\right)$ shows the income potential of a city without urban rent and population. Two equilibrium points are not of our interest these are in Yr-plane and in Pr-plane respectively, because for an urban area, population and income could not be assumed to zero though there growth might be zero. Finally of the two equilibrium points that are of our interest, one is on PY-plane where $r$ will be zero and the last seventh point is in space where all three variables are non-zero.

Equilibrium of three dimensional non-linear systems generally achieved hyperbolic steady state and the hyperbolic steady state condition was more reliable as compared to Non-Hyperbolic Steady state conditions. To find the eigen values for analyzing steady state conditions of the non-linear system, we apply the standard linearization method of Jacobian Matrix. However, the complete analysis of stability required estimates of the 11 parameters because we used the panel fixed effect regression technique. We used data of thirty international cities to simulate the model and solving the model numerically using RungeKutta 4th order Method using Matlab ode45 function. We plot the phase plot of the simulations trajectories and also plot the indicators over time.

\section{Data sources and profile of selected cities}

For the empirical estimation of parameters of the three dimensional Lotka Volterra Model, the present study chose thirty international mega cities and divided these cities into five categories according to the definition of global 
cities, provided by a report of Brooking Institute in 2016 (Trujillo and Parilla 2016). Only country specific categories of global cities have been selected. They are described below:

- Global giants: These extremely large, wealthy urban areas are hubs for financial markets or major corporations, and they serve as key nodes in global capital and talent flows.

- Asian anchors: Asian anchors are not as wealthy as their global giant counterparts, but they play a similar role as command centers in fast-growing Asia by drawing on their infrastructure connectivity and talented workforces to attract the most foreign direct investment (FDI) of any metro grouping.

- Emerging gateways: These metros have grown healthily to reach middleincome status, but they lag on many key competitiveness factors compared to their global peers.

- Knowledge capitals: Knowledge capitals with talented workforces and elite research universities. These regions are at the world's innovation frontier, and thus they are challenged constantly to generate new knowledge and ideas to sustain growth.

- International middleweights: International middleweights are globally connected by people and investment flows but still experiencing lagging growth since the financial crisis. Like their American middleweight peers, they are striving for a post-recession niche in the global economy, to varying degrees of success.

Table 1: Five types of global selected cities, 2015

\begin{tabular}{ll}
\hline Group name & Cities \\
\hline Global giants & London, New York, Paris, Tokyo \\
Asian anchors & $\begin{array}{l}\text { Beijing, Moscow, Seoul, Shanghai, Singa- } \\
\text { pore }\end{array}$ \\
Emerging gateways & $\begin{array}{l}\text { Katowice, Mexico City, Santiago, Warsaw, } \\
\text { Knowledge capitals } \\
\text { Atlanta, Boston, Minneapolis, Philadel- } \\
\text { phia, San Francisco, Seattle, Stockholm, } \\
\text { International mid- } \\
\text { dleweights }\end{array}$ \\
& $\begin{array}{l}\text { Brussels, Copenhagen, Milan, Amsterdam, } \\
\text { Vienna, Athens, Barcelona, Berlin, Syd- } \\
\text { ney, Toronto }\end{array}$ \\
\hline
\end{tabular}

The study extracts data of the required variables from OECD State website and the specific cities websites. Urban rent and land price data was derived from Rent-Income ratios and Price-Income ratios. We interpolate the data of missing years using linear interpolation. Duration of the data is from year 2000 to year 2016.

\section{Empirical estimation of parameters and simulations}




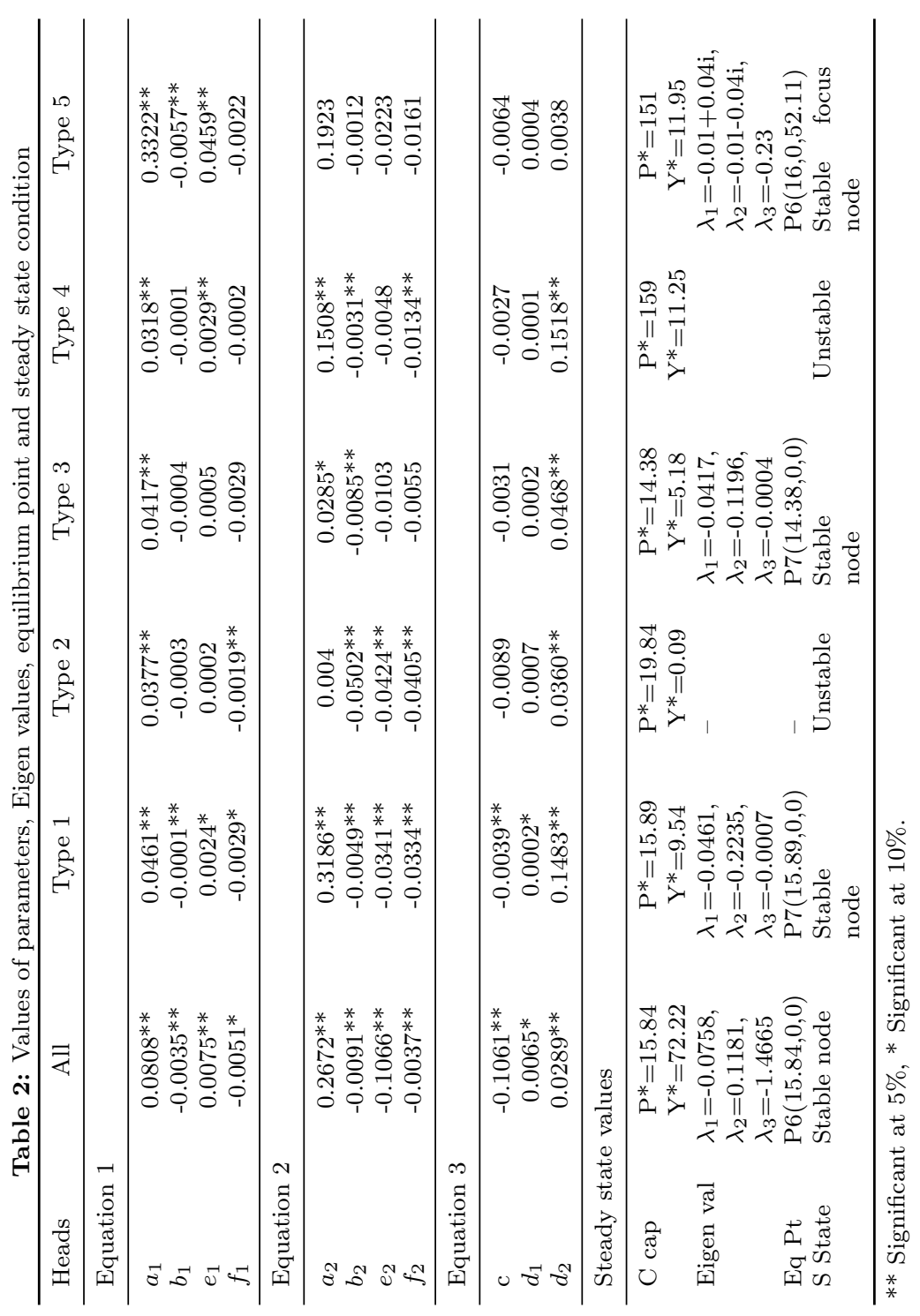


We used panel fixed effect regression to estimate the value of parameters. Fixed effect removed the pernicious effect of omitted variable bias and enabled the researchers to observe the interaction effects of the three variables. Estimated values of parameters have expected signs as the model describes. Few estimates are not significant at $5 \%$ or $10 \%$ percent level of significance. However, the signs are as described in the model in the groups/ types. Therefore, it is confirmed that the three variables comprehensively, describe the urban life cycle for the mega cities overall as well as of all five types of cities. Table 2 presents the empirical estimates of parameters as well as the eigen values, steady state equilibrium position and stability condition at steady state position.

All parameters are significant at $5 \%$ in the all cities regression except coefficient of population in the first equation and coefficient of population in the rent equation. These two variables are significant at $10 \%$ level of significance.

Table 3 presents the phase plots and series plots of the simulation of model by type of cities. In dynamics of urban life cycle of all thirty cities, population does not play any significant role however the dynamics between per capita income and urban rent could be observed clearly in the series plot of all cities. The urban rent as proxy of urban living cost lagged to per capita income as proxy of favorable environment for living in urban areas. The cyclic behavior between urban rent and per capita income with a small feedback effect on population is apparent. Though the steady state would be achieved as Stable Node fixed when the dynamics between urban rent and per capita income would be stable at the point where only population will remain constant.

Type 1 cities are global giants, their income generating capacity is at the peak level and they are carrying population above their carrying capacity. In the series plot, per capita income declines and the cost of living increases. The population also decreases, which confirms the implications of three dimensional Lotka Volterra Model behavioral interaction of the three variables. However, in the later stage, role of per capita income declines and the dynamics remain the same with population and urban rent. The per capita appreciation in the later stage only provides feedback effect to some extent to attract population. The steady state would be Stable Node around the carrying capacity of population.

Steady state condition of Type 2 cities would be Unstable; this seems to be the feedback effect of high rising growth of population and the low level of per capita income. However, the dynamics remain the same between the population and the urban rent. Therefore, the attraction of the population is towards better living environment. The same kind of trends can be observed in other types of cities such as Type 3, Type 4 and Type 5. The actual attraction for the population is the living cost. Type 3 cities steady state equilibrium condition would be Stable Node around the carrying capacity of population though the Type 4 would be the Un-Stable system. Type 5 cities steady state equilibrium condition would be Stable Focus Node. 
Table 3: Phase plot and series plot of simulations by type of cities

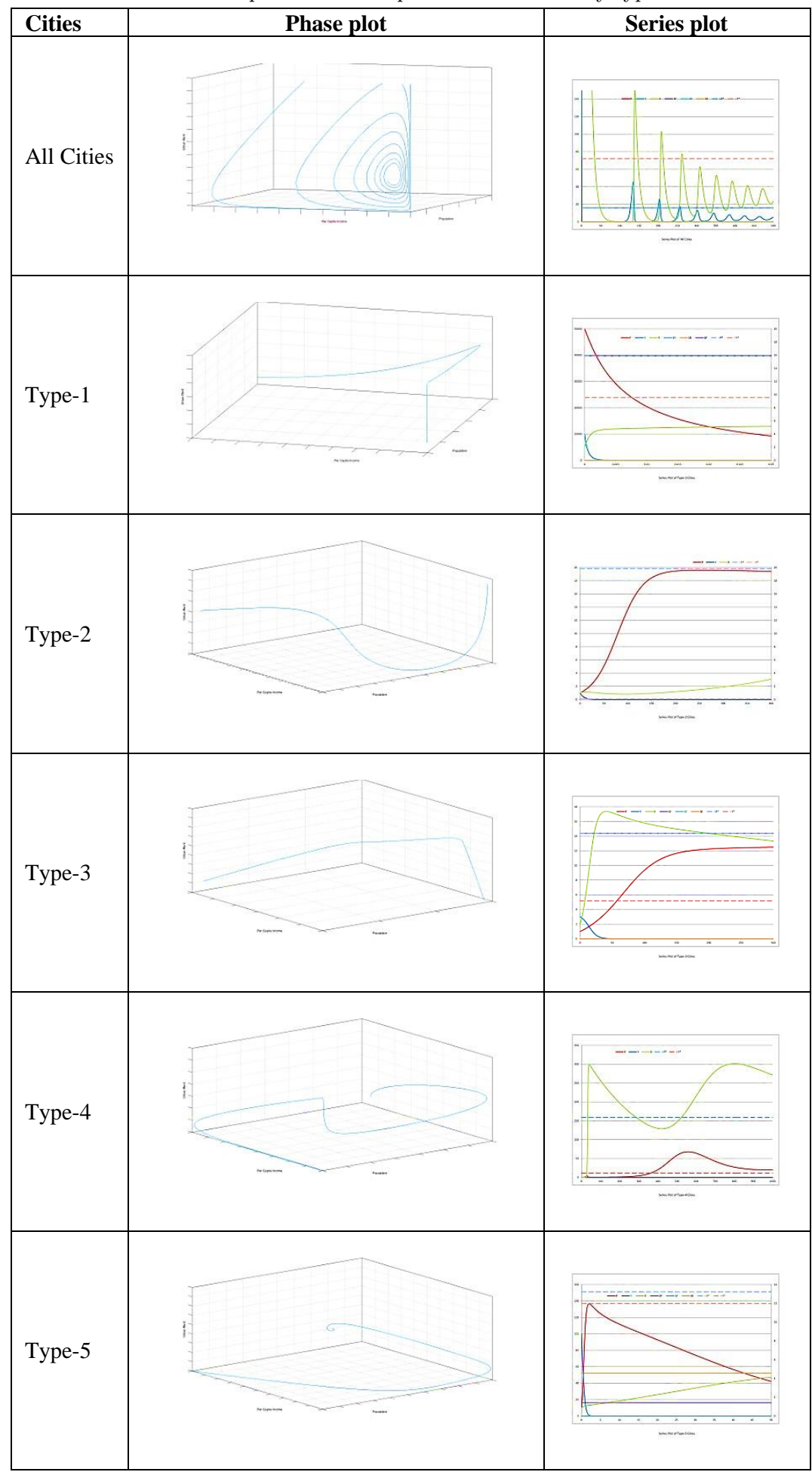




\section{Conclusion}

The three dimensional Lotka Volterra Model was estimated empirically and simulated with the real data of thirty international mega cities using panel fixed effect regression model. The estimated parameters showed the expected signs means the model was successfully implemented to all cities data as well as to the group of five types of cities with different levels of significance.

However, our analysis with the simulations of the model suggested that in the future the actual force of attraction for urban population would be the low cost of living and the living conditions such as better environment. Per capita income does not play any significant role for the attraction of population. Therefore, we observed relatively high population growth in the types of cities where the growth of living cost is relatively lower than the other types. Per capita income provides feedback to control the chaos between population and urban rent and plays the role of a driving force in the urban dynamics. The cities with better environmental conditions with low cost would be more attractive as compared to the cities with high growth of living cost as well as high level of per capita income. The model we adopted in this research paper is completely explained through theoretical and mathematical structure. The most important element of our three dimensional model is that living cost and better environmental conditions govern the economic dynamics and demographic processes of activity of relocation of population.

\section{References}

Berg Lvd, Drewett R, Klaasen LH, Rossi A, Vijverberg CH (1982) Urban europe: A study of growth and decline. The Costs of Urban Growth (curb) Project 1

Bourne LS (1996) Reinventing the suburbs: old myths and new realities. Progress in planning 46(3):163-184

Camagni R (2016) Afterthoughts on urban economic theory and its focus. Investigaciones regionales: Journal of Regional Research (36):87-105

Dendrinos DS, Mullally H (1981) Evolutionary patterns of urban populations. Geographical Analysis 13(4):328-344

Dendrinos DS, Mullally H (1983) Optimum control in nonlinear ecological dynamics of metropolitan areas. Environment and Planning A 15(4):543-550

Klaassen LH, Bourdrez JA, Volmuller J (1981) Transport and reurbanisation

Lever WF (1993) Reurbanisationthe policy implications. Urban studies 30(2):267-284

Lotka AJ (1926) Elements of physical biology. Science Progress in the Twentieth Century (1919-1933) 21(82):341-343

Orishimo I (1987) An approach to urban dynamics. Geographical analysis 19(3):200-210

Trujillo JL, Parilla J (2016) Redefining Global Cities: The Seven Types of Global Metro Economies. Brookings Institution

Volterra V (1931) Théorie mathématique de la lutte pour la vie. Gauthiers-Villars 